\title{
The goggles experiment: can chimpanzees use self-experience to infer what a competitor can see?
}

\author{
Katja Karg ${ }^{\text {a, * }}$, Martin Schmelz a, Josep Call ${ }^{\text {a, b }}$, Michael Tomasello ${ }^{\text {a }}$ \\ a Max Planck Institute for Evolutionary Anthropology, Leipzig, Germany \\ ${ }^{\mathrm{b}}$ School of Psychology and Neuroscience, University of St Andrews, St Andrews, U.K.
}

\section{A R T I C L E I N F O}

\section{Article history:}

Received 12 January 2015

Initial acceptance 4 March 2015

Final acceptance 17 April 2015

Available online 26 May 2015

MS. number: 15-00027

\section{Keywords:}

chimpanzee

experience projection

perspective taking

social cognition

theory of mind

\begin{abstract}
In two experiments, we investigated whether chimpanzees, Pan troglodytes, can use self-experience to infer what another sees. Subjects first gained self-experience with the visual properties of an object (either opaque or see-through). In a subsequent test phase, a human experimenter interacted with the object and we tested whether chimpanzees understood that the experimenter experienced the object as opaque or as see-through. Crucially, in the test phase, the object seemed opaque to the subject in all cases (while the experimenter could see through the one that they had experienced as see-through before), such that she had to use her previous self-experience with the object to correctly infer whether the experimenter could or could not see when looking at the object. Chimpanzees did not attribute their previous self-experience with the object to the experimenter in a gaze-following task (experiment 1); however, they did so successfully in a competitive context (experiment 2). We conclude that chimpanzees successfully used their self-experience to infer what the competitor sees. We discuss our results in relation to the well-known 'goggles experiment' and address alternative explanations.
\end{abstract}

๑ 2015 The Association for the Study of Animal Behaviour. Published by Elsevier Ltd. All rights reserved.
Mentalizing, or possessing a 'theory of mind', refers to the ability to ascribe unobservable mental states to oneself and others (Premack \& Woodruff, 1978). Whether this ability is uniquely human or shared with nonhuman primates is still highly controversial. Advocates of great apes' mentalizing capabilities can by now list an abundance of studies that support their view (for reviews, see Andrews, 2005; Call, 2007; Call \& Tomasello, 2008; Whiten, 2013). In contrast, sceptics are still not convinced and explain positive results by nonmentalistic processes, such as associative learning or inferences based on nonmentalistic categories (Heyes, 1998; Penn \& Povinelli, 2007; Povinelli \& Vonk, 2004). Some theorists doubt that distinguishing reasoning about another's mind from responding to behavioural cues alone will ever be possible, as inferences about another's mental state are inevitably based on their behaviour (Lurz, 2009; Purdy \& Domjan, 1998; Shettleworth, 2010).

Heyes (1998) proposed one way to distinguish mentalizing skills from nonmentalistic processes. The design was later refined by Povinelli and Vonk $(2003,2004)$ and became known as the 'goggles

\footnotetext{
* Correspondence: K. Karg, Department of Developmental and Comparative Psychology, Max Planck Institute for Evolutionary Anthropology, Deutscher Platz 6, 04103 Leipzig, Germany.

E-mail address: katja_karg@eva.mpg.de (K. Karg).
}

experiment'. In this theoretical study, primate subjects first gain experience with two pairs of mirrored goggles in a training phase. From the outside, both goggles differ only in their rim colour. However, when wearing them, subjects experience one as opaque and the other as transparent. In the subsequent test phase, two experimenters wear the goggles such that one can see, while the other cannot. The subject is now allowed to beg for food from one of the experimenters. If primates are able to mentalize, they should use their own mental experience to infer the others' mental states, and prefer begging from the experimenter who wears the seethrough goggles. Crucially, subjects never observe others interacting with the goggles, so effects from observational learning can be excluded.

Although well known and perhaps the clearest way of demonstrating mentalism in a nonverbal animal, there have since been few attempts to implement the study. Penn and Povinelli reported negative results for chimpanzees, Pan troglodytes, in a study in which they used (instead of goggles) buckets with opaque or seethrough visors (Vonk \& Povinelli, 2011). In contrast, Meltzoff and Brooks (2008) conducted a study with 18-month-old infants that resembled the goggles experiment. They provided two groups of children different experience with the view-obstructing properties of blindfolds. Both blindfold types looked opaque from the outside, but one could see through the 'trick blindfolds' when they were 
close to one's eyes, whereas the others were opaque and one could not see through them, even when they were close to one's eyes. After this experience phase, the infants' understanding of the other's sight was tested in a gaze-following task. A blindfolded experimenter sat opposite the child and looked at a target object to her left or right. The authors found that children who had experienced the opaque blindfolds followed the experimenter's gaze less than those who had experienced the trick blindfolds. Infants thus used their self-experience to infer what a blindfolded experimenter could see.

Like infants, chimpanzees follow conspecifics' and humans' gaze (e.g. Tomasello, Call, \& Hare, 1998; Tomasello, Hare, \& Agnetta, 1999). We thus decided to test chimpanzees' mentalizing abilities in an experiment similar to the infant study. Instead of blindfolds, we used 'face masks' that could be held in front of the eyes of the subject (experience phase) or the experimenter (test phase). One mask was opaque, the other a trick mask that looked opaque from the outside, but could be seen through when it was close to the eyes. In the test, a masked experimenter looked at a target object to her left or right, and we measured the subject's gaze-following response. We hypothesized that if chimpanzees were able to use their own experience to infer what the other can see, they would follow the experimenter's gaze less if they had experienced the opaque mask compared to the trick mask.

In a second experiment, we used a competitive paradigm to test the same question: can chimpanzees use their self-experience to infer what the experimenter sees? Previous research has shown that chimpanzees are more skilful in competitive than cooperative contexts (Hare \& Tomasello, 2004). We thus hypothesized that it might be easier for chimpanzees to predict the other's perspective in this paradigm.

\section{EXPERIMENT 1}

\section{Methods}

\section{Subjects}

Subjects were 25 chimpanzees (11 males, 14 females) living at the Ngamba Island Chimpanzee Sanctuary in Lake Victoria, Uganda (mean age $15.5 \pm 3.2$ years, range $8-22$ years; www.ngambaisland. org). All apes came to the sanctuary as orphans as a result of the illegal bushmeat trade, were raised by humans together with peers, and at the time of testing lived in social groups. All of them had experience with experimental testing due to previous research at the sanctuary. Subjects were fed according to their regular diet and were never food or water deprived.

\section{Apparatus}

The subject was tested individually inside the holding facility. The experimenter sat opposite the subject, at a distance of about $60 \mathrm{~cm}$. There was a rectangular black board on the floor $(50 \times 100 \mathrm{~cm}$ ) between the experimenter and the subject (Fig. 1). Three cameras recorded the session. One was placed behind the experimenter and recorded her movements to keep track of the experimental conditions; the other two cameras were to the left and right of the experimenter, $135 \mathrm{~cm}$ from the subject, at a height of $150 \mathrm{~cm}$, and provided a close-up of the subject's face and upper body to keep track of her looking behaviour. Two identical, colourful plastic toys $(25 \mathrm{~cm}$ high $\times 15 \mathrm{~cm}$ wide) hung right underneath the cameras as potential gaze targets.

We used four types of 'face masks', each shaped like a hand mirror (Fig. 2). A mask consisted of a yellow or blue frame $(26 \times 26 \mathrm{~cm})$ on a handle bar $(15 \mathrm{~cm}$ long, $4 \mathrm{~cm}$ diameter $)$ and an opaque or fly screen inner layer $(21 \times 21 \mathrm{~cm})$, resulting in the four different mask types: opaque-yellow, opaque-blue, screen-yellow

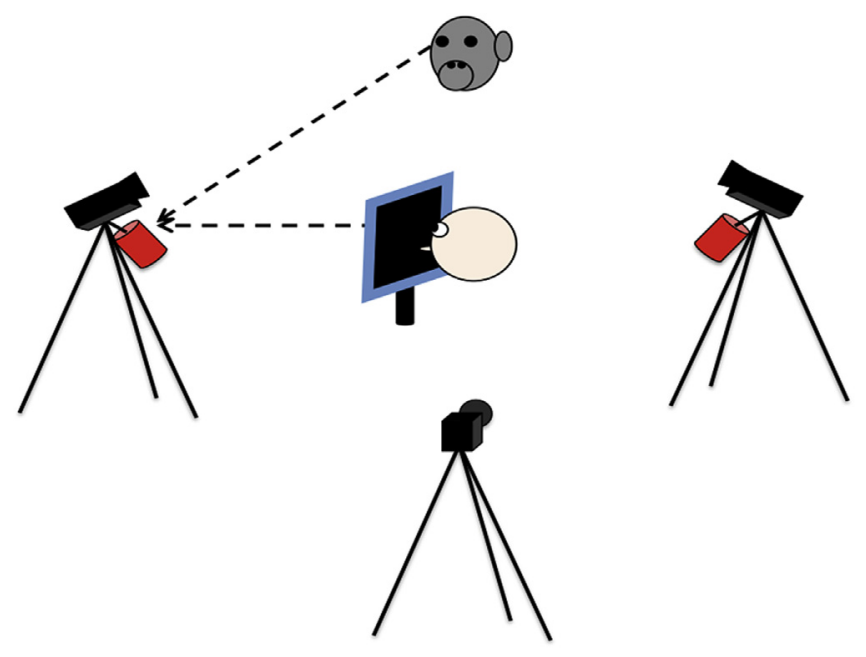

Figure 1. Set-up of experiment 1 . In the test phase, the chimpanzee sat opposite the experimenter who was wearing a face mask and orienting towards a colourful object underneath the camera that recorded the subject's gaze-following behaviour.

and screen-blue. One could see through the fly screen when looking straight through, but not if looking from the side. The opaque and the screen layers looked the same when placed on a black surface (see Fig. 2). To maximize the similarity between both inner layer types, we added a layer of fly screen on top of the opaque layer, so that the surface structure was the same for both mask types. In the experience phase, we used small, colourful toys $(7 \times 11 \mathrm{~cm})$ and pieces of fruit to draw the animal's attention to the mask. We did so by first showing the animal the object (toy or fruit) and subsequently positioning the mask between the subject's eyes and the object, such that she would look at the mask.

\section{Procedure and design}

Each subject received two conditions in separate sessions on 2 consecutive days. We modelled our procedure as closely as possible on the infant study by Meltzoff and Brooks (2008). Each daily test session was split into the following two phases.

Experience phase. Subjects could gain experience with the properties of one mask type for $8 \mathrm{~min}$; on the next day, she would experience the other mask type. The experimenter sat down in front of the subject and placed pieces of fruit or colourful toys on

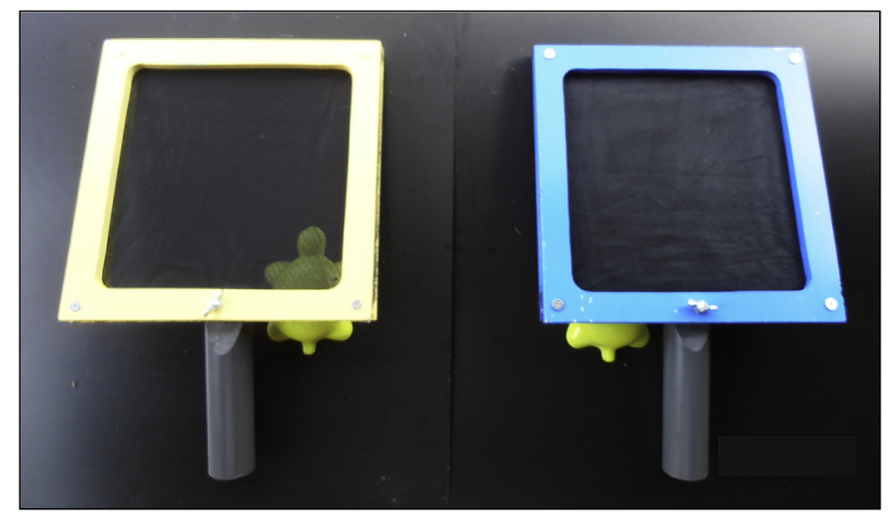

Figure 2. Pictures of the face masks for experiment 1 as an example of the chimpanzees' experience in the training phase. On the left, the colourful toy on the black board is visible through the screen mask, whereas on the right, the toy is hidden behind the opaque mask. 
the black board between them. When the subject fixated the object, the experimenter interposed the mask between the object and the subject's eyes, such that the subject could learn about the mask's properties (opaque/transparent, depending on condition). Subjects did not avoid looking at the mask and generally maintained their gaze direction after the mask was interposed, resulting in their looking at the mask. Multiple object exemplars in multiple spatial locations on the board were used to demonstrate that the screen mask did not block vision, and that the opaque one did. At the beginning of the experience phase, the experimenter held the mask close to the object, approximately $40 \mathrm{~cm}$ from the subject's eyes. In the course of the $8 \mathrm{~min}$, she decreased the distance between the mask and the subject's eyes up to a distance of about $10 \mathrm{~cm}$. Even when the mask was close to the chimpanzees' eyes, they sat still and maintained their general gaze direction, thus not showing signs of an avoidance reaction to the mask.

Test phase. After the experience phase, we tested the chimpanzee's understanding of the effect of the particular mask type on the experimenter's sight in a gaze-following task. First, the experimenter started an electronic device that gave an acoustic signal every second to keep track of the time. At the beginning of each trial, the experimenter approached first the right, then the left camera and examined the plastic toys to draw the subject's attention to them. She then sat down opposite the chimpanzee and fed her, with the mask lying on the black board in front of her. After about $1 \mathrm{~min}$, she picked up the mask, held it close to her face, turned her masked face (and head) 90 degrees towards the left or right camera (according to a predefined scheme, never to the same side more than twice in a row, and left and right side counterbalanced), and remained with her face aligned with the camera for $7 \mathrm{~s}$. Next, she laid down the mask and fed one to three more pieces of food to the subject before the next trial started. Crucially, in the test phase, the opaque inner layer was always inserted in the mask, such that in both conditions the mask really was opaque (and the experimenter was just staring at the inside of the mask, but her gaze direction aligned with the camera). We administered eight test trials per session, with a 3 min repetition of the experience phase after the first four trials to remind the subjects of the mask's properties.

Each subject received each of the two conditions in separate sessions on 2 consecutive days. Twelve of the subjects started with the opaque condition; the other 13 started with the screen condition. In each of the two condition groups, half of the subjects started with a yellow frame and the other half with a blue frame. In their following session, they received the other condition with the other colour. The resulting four groups were counterbalanced for age and sex.

\section{Coding and analysis}

We used the recorded data from all three cameras for the analysis. First, we determined the relevant looking time intervals (the $7 \mathrm{~s}$ in which the experimenter looked at the target) by analysing the central camera data that focused on the experimenter's head. We then analysed the recordings of the left and right camera separately for all looks to the camera within the $7 \mathrm{~s}$ per trial in which the experimenter looked towards the camera. Looks were coded as 'camera look' when the chimpanzee lined up his or her eyes with a camera for at least $0.33 \mathrm{~s}$ (eight video frames). We differentiated the camera looks depending on whether the subject looked at the same camera as the experimenter ('correct look'), or at the other one ('incorrect look'). As subjects rarely looked at the cameras more than once within a $7 \mathrm{~s}$ trial, we coded presence or absence of at least one correct/incorrect look per trial and analysed the proportion of trials with correct and incorrect looking for each individual. In trials in which the subject's eyes were not aligned with the camera (or in which subjects only glanced at the camera for less than $0.33 \mathrm{~s}$ ), no correct or incorrect looks were coded.

For a better comparison to Meltzoff and Brooks' (2008) between-subjects study with infants (who received only four trials each), we additionally analysed only the first four trials of each subject's first session (resulting in a between-subject analysis of our originally within-subject data). Following Meltzoff and Brooks (2008), we scored the subject's first target look for each trial as either a correct look $(+1)$ or an incorrect look $(-1)$. If subjects did not look at either target during the $7 \mathrm{~s}$ trial, they received a score of 0 . We then calculated a looking score for each subject as the sum of correct looks, incorrect looks and nonlooks (as is routinely done in gaze-following studies with children, e.g. Butler, Caron, \& Brooks, 2000; Dunphy-Lelii \& Wellman, 2004). Thus, the possible range for the looking scores across the first four trials varied from -4 to +4 .

An independent observer coded a randomly selected $20 \%$ of the sessions. He was naïve to all test parameters. Interobserver agreement was assessed by Spearman correlation and was good for both the number of correct $\left(r_{S}=0.78, P<0.01\right)$ and incorrect looks $\left(r_{\mathrm{S}}=0.89, P<0.01\right)$.

\section{Results}

The different experiences with the visual properties of the mask (opaque/transparent) did not affect the chimpanzees' gazefollowing behaviour towards the experimenter wearing that mask (repeated measures ANOVA with condition, order and sex as between-subject factors: $F_{1}, 21=0.012, P=0.913, \eta^{2}=0.001$ ). In both conditions, chimpanzees looked at the correct camera in about $60 \%$ of the trials, whereas they looked at the incorrect camera in about $33 \%$ of the trials (Fig. 3).

We used a one-way ANOVA to assess the chimpanzees' looking scores in their first four trials. Chimpanzees' looking scores did not differ between the opaque and the screen condition $\left(F_{1,23}=1.03\right.$,

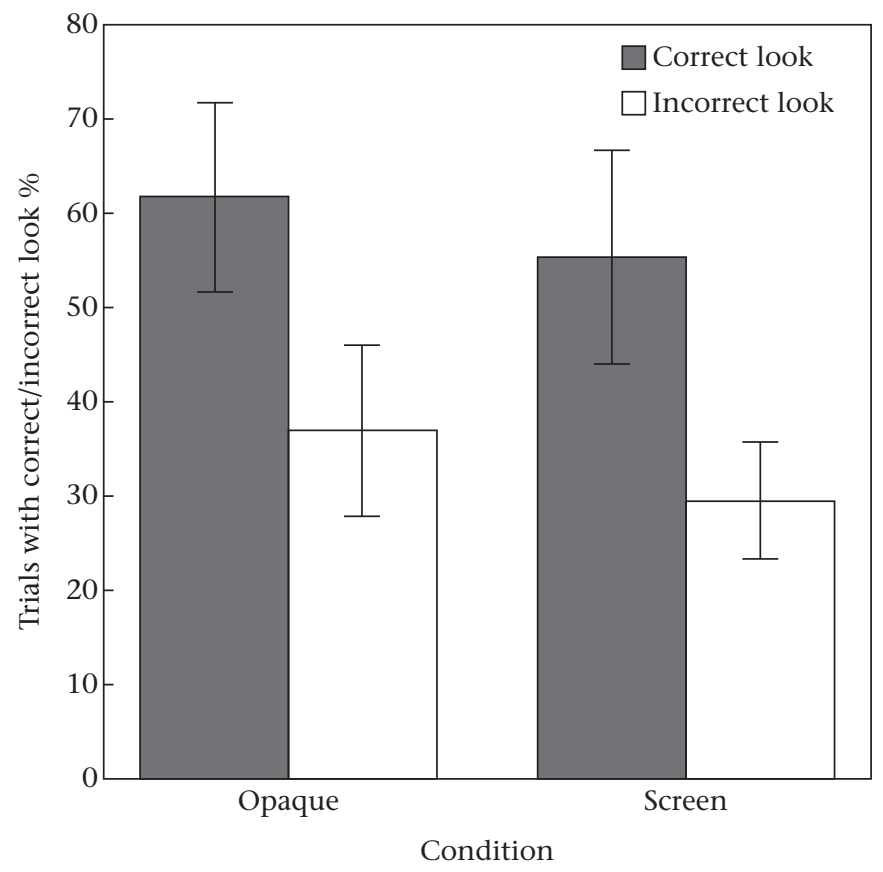

Figure 3. Mean percentage of trials with at least one correct or one incorrect look in the opaque and screen conditions. Error bars refer to $95 \% \mathrm{CI}$ 
$P=0.32$ ), although on average they looked at the target less often in the opaque condition (mean $=1.00,95 \%$ confidence interval, $\mathrm{CI}$ $[-0.05,2.05])$ compared to the screen condition (mean $=1.69,95 \%$ CI $[0.63,2.75])$. Overall, chimpanzees' looking scores were higher than infants' looking scores in both conditions (infants: opaque condition: mean $=0.12 \pm 1.15$; screen condition: mean $=1.04 \pm$ 1.37; Meltzoff \& Brooks, 2008).

\section{Discussion}

In this experiment, we adapted a study recently conducted with 18-month-old infants (Meltzoff \& Brooks, 2008) for chimpanzees to test their mentalizing abilities. We did not observe any difference in chimpanzees' gaze-following behaviour towards an experimenter who was wearing a mask depending on whether they had experienced that the mask was opaque or transparent. We conclude that there is no evidence that chimpanzees in this study used their own visual experience to infer what another can see. In contrast, 18month old infants followed the gaze of a blindfolded experimenter more when they had experienced see-through than opaque blindfolds (Meltzoff \& Brooks, 2008).

This difference in the results of chimpanzees and infants could be due to the methodology, as we used masks instead of blindfolds. However, as the masks covered the whole face instead of just the eyes, this should have made the manipulation more obvious, not less.

Gaze following could also have a different ecological significance for chimpanzees and children. Following another's gaze in the rainforest as quickly as possible might be a highly adaptive response with little energetic costs. The behaviour might be more automatic and quick in chimpanzees than in humans, which could render it unsuitable to capture higher cognitive processes such as the computation of another's perspective. In our experiment, the costs of following the experimenter's gaze were particularly low as the subject did not have to switch position to see the gaze target. This is reflected by the relatively high rates of gaze following (about $60 \%$ of trials) that chimpanzees in our study showed despite the opaque face mask in front of the experimenter's eyes. A study by Okamoto-Barth, Call, and Tomasello (2007) measured great apes' gaze-following behaviour towards an experimenter who was either looking through a window or at an opaque barrier $(50 \mathrm{~cm}$ from the experimenter's face). Chimpanzees followed the experimenter's gaze to the target object in the window condition more (about 60\%) than in the opaque condition (about 30\%). Chimpanzees in our experiment hence treated the face mask more like a window than an opaque barrier, but did so independent of condition. One reason for this might be that our subjects face more ecological challenges (e.g. snakes, more food competition) than the zoo animals in the study by Okamoto-Barth et al. (2007), and they might thus be more sensitive to gaze. It could also be that a flat barrier close to one's face is rather rare and its effect less often experienced in everyday life (and thus more likely not be taken into account) than gaze-obscuring obstacles at some distance from another individual's eyes. Overall, our results also support previous findings that chimpanzees are more sensitive to the role of head movements when following gaze compared to the role of the eyes (see Tomasello, Hare, Lehmann, \& Call, 2007).

Several studies have shown that chimpanzees take into account the geometric constellation of the looker and the object (OkamotoBarth et al., 2007; Tomasello et al. 1999) and that adult, but not infant, chimpanzees habituate when confronted with an experimenter who repeatedly looks towards nothing (Tomasello, Hare, \& Fogleman, 2001). These results suggest that there is at least some degree of flexibility in chimpanzees' gaze-following behaviour.

\section{EXPERIMENT 2}

In a second experiment, we used a competitive game to test the same question as in experiment 1 , since competitive contexts have been very successful in uncovering cognitive skills of chimpanzees (Hare \& Tomasello, 2004). Our set-up and procedure was inspired by a study from Melis, Call, and Tomasello (2006). We first established a competitive context by taking away food that the chimpanzee was trying to obtain and that the experimenter could see. In the subsequent test phase, the experimenter sat opposite the chimpanzee with food in boxes to her left and right side. The boxes had different lid types: opaque, transparent or screen. The opaque and the transparent lids did not change their visual properties between their opened and their closed position. In contrast, subjects could see through the screen in its open position, but not when it was closed (the experimenter could, from her perspective, see through the screen in both its open and its closed position). Subjects were first familiarized with the visual properties of the lids; then the lids were closed and the subject could choose to steal food from one of the two boxes: opaque versus transparent box (transparent condition) or opaque versus screen box (screen condition). In a nonsocial control, we tested chimpanzees' general preference to reach into the opaque box (compared to a transparent box), independent of the presence of a human competitor.

Melis et al.'s procedure was basically the same, but with tunnels instead of boxes, and only two different tunnel types: opaque versus transparent. The subject could then reach the food either through an opaque tunnel that hid her approaching hand or through a transparent tunnel that did not prevent the experimenter from observing the reach. Subjects had a significant preference for reaching through the opaque tunnel, but this preference disappeared in a nonsocial control. While our transparent condition basically replicated Melis et al.'s experiment, the screen condition was the key to testing chimpanzees' mentalizing abilities. We hypothesized that if subjects were able to use their experience with the lid properties to infer what the experimenter sees, they would prefer to steal from the opaque box, in which their hand was hidden from the experimenter's view. They would not show such a preference when the human competitor was absent.

\section{Methods}

\section{Subjects}

Subjects were 19 semifree-ranging chimpanzees at the Ngamba Island Chimpanzee Sanctuary in Lake Victoria, Uganda (www. ngambaisland.org; nine females, 10 males; age range 8-17 years, mean $=14.3$ years). All but one young male (Rambo, 8 years) had participated in experiment 1 before. All except one male (Kisembo, 14 years) passed the criterion that ensured that they understood the competitive nature of the game, so 18 chimpanzees proceeded to the test. Subjects were fed according to their regular diet and were never food or water deprived.

\section{Apparatus}

The experimenter sat opposite the subject, $50 \mathrm{~cm}$ from the enclosure (Fig. 4). The bars between the experimenter and the subject were occluded ( $60 \mathrm{~cm}$ high, $100 \mathrm{~cm}$ wide).

There were two boxes to the experimenter's left and right side $(40 \times 13 \mathrm{~cm}, 25 \mathrm{~cm}$ high on subject's side; $65 \mathrm{~cm}$ apart). Two sliding food trays could be inserted in the boxes and moved away from or closer to the subject by a handle bar. The subject could reach the food by sliding up a transparent trap door $(10 \times 8 \mathrm{~cm})$ at the box side facing her and then reaching through a hole into the box ( $6.5 \mathrm{~cm}$ diameter). The boxes had exchangeable lids, so that they could be transparent, opaque or covered with four layers of 

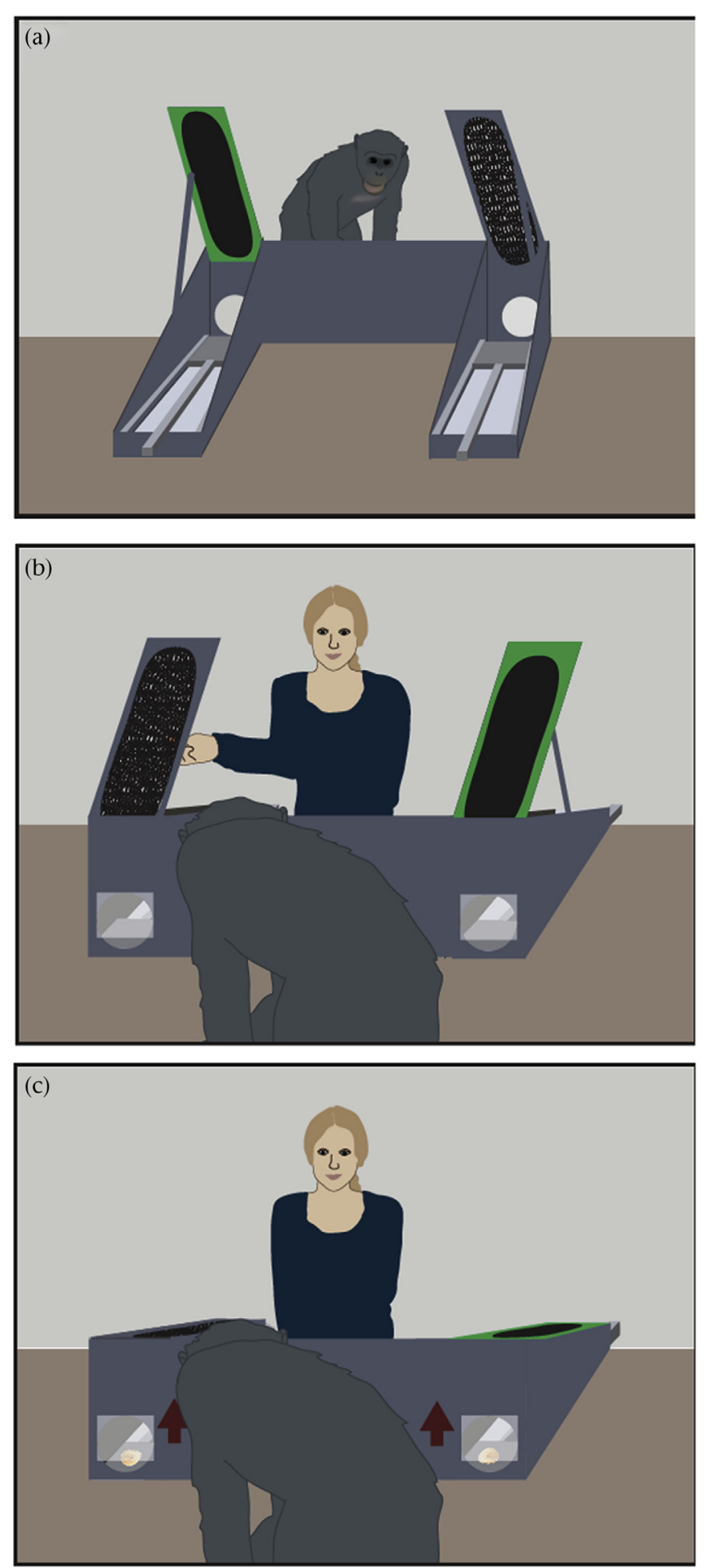

Figure 4. Set-up of experiment 2. (a) Apparatus with open lids from the experimenter's perspective. (b) Training phase. The chimpanzee can see the peanuts through the screen lid on his left side, but not through the opaque lid on his right side. (c) Test phase. Both lids are closed and the boxes are baited with pieces of banana. Both lids now appear opaque to the subject, whereas the experimenter can still see through the screen. The chimpanzee can now decide to lift and reach through one of the trap doors to steal the piece of banana from the box. Note that the space between the chimpanzee and the experimenter was occluded up to a height of $60 \mathrm{~cm}$ (lower breast height of the experimenter; not depicted in the picture) such that the experimenter could not see which side the chimpanzee chose until observing the subject's hand in one of the boxes. black fly screen. To maximize the similarity in surface structure between the opaque and the screen lid, we fixed a layer of fly screen on the opaque lid. The lids could be brought into a stable open position (40 degrees above horizontal), such that the subject would have a good view of the visual properties of the lids, in particular to experience the screen as see-through. When the lids were closed, the subjects could still see through the transparent lid, and could not see through the opaque lid. However, the screen lid changed its apparent properties: the subject could now no longer see through it (see Fig. 5, for pictures). In contrast, the experimenter was still able to see through the screen from her perspective.

\section{Procedure and design}

Each subject first had to pass a criterion training and, if successful, received three conditions in randomized order: the nonsocial control, the transparent and the screen condition. Subjects received each condition in two consecutive sessions with 12 trials each, i.e. 24 trials per condition and 72 trials in total.

Training. To familiarize subjects with the competitive nature of the task, subjects learnt that the experimenter would retrieve the food if she could see the subject reaching for it. The experimenter sat opposite the subject, with the two boxes to her left and right side. Both box lids were transparent and, at the beginning of each session, open. To demonstrate the transparency of the lids, the experimenter showed the subject five peanuts through each of the lids, starting on her right side and then taking turns. Next, the experimenter closed the lids. The trial started with the experimenter baiting the boxes, with the food out of reach of the subject. She centred the subject by placing some peanuts between the boxes, $160 \mathrm{~cm}$ above the ground. While the subject was climbing up to get the peanuts, the experimenter pushed the food towards the trap doors and turned with her head and body towards one of the boxes (left and right side counterbalanced within a session, with the constraint that the orientation could not be the same in more than two consecutive trials), so she could see the food item she was oriented towards, but not the other. When the subject climbed back down, the subject first saw the two lid types from above (see Fig. 5), and when down on the floor she could see both food items through the transparent trap doors. However, when the subject tried to grab the food item that the experimenter was looking at, the experimenter pulled it back. When the subject tried to grab the other piece, she was allowed to obtain it. After the subject had made a decision, both trays were pulled back, and the next trial started. Each session included 12 trials. Subjects had to choose the correct side in at least 10 out of 12 trials in two consecutive sessions to proceed to the test. If they did not succeed within 10 sessions, they were dropped from the study.

Test phase. Each test session started with six warm-up trials as in the training. They served to ensure the motivation of the subject on the test day. The subjects proceeded to the actual test trials only if they chose the correct side in at least five out of six warm-up trials (only two subjects failed and successfully restarted their session on the following day). Each test trial started with opening the lids, and demonstrating the lid properties that differed between the sides (transparent/opaque/screen) to the subject by showing her a peanut, moving it behind the lid and back to the centre. The peanut was then given to the subject. Two peanuts were presented on each side, always starting with the right side and then taking turns. Then the lids were closed and the trays baited. The experimenter centred the subject as in the training. While the subject was climbing up to get the peanuts, the experimenter pushed the food towards the trap doors. She remained with her upper body and head centred, so that she could observe both boxes. When the subject tried to reach 

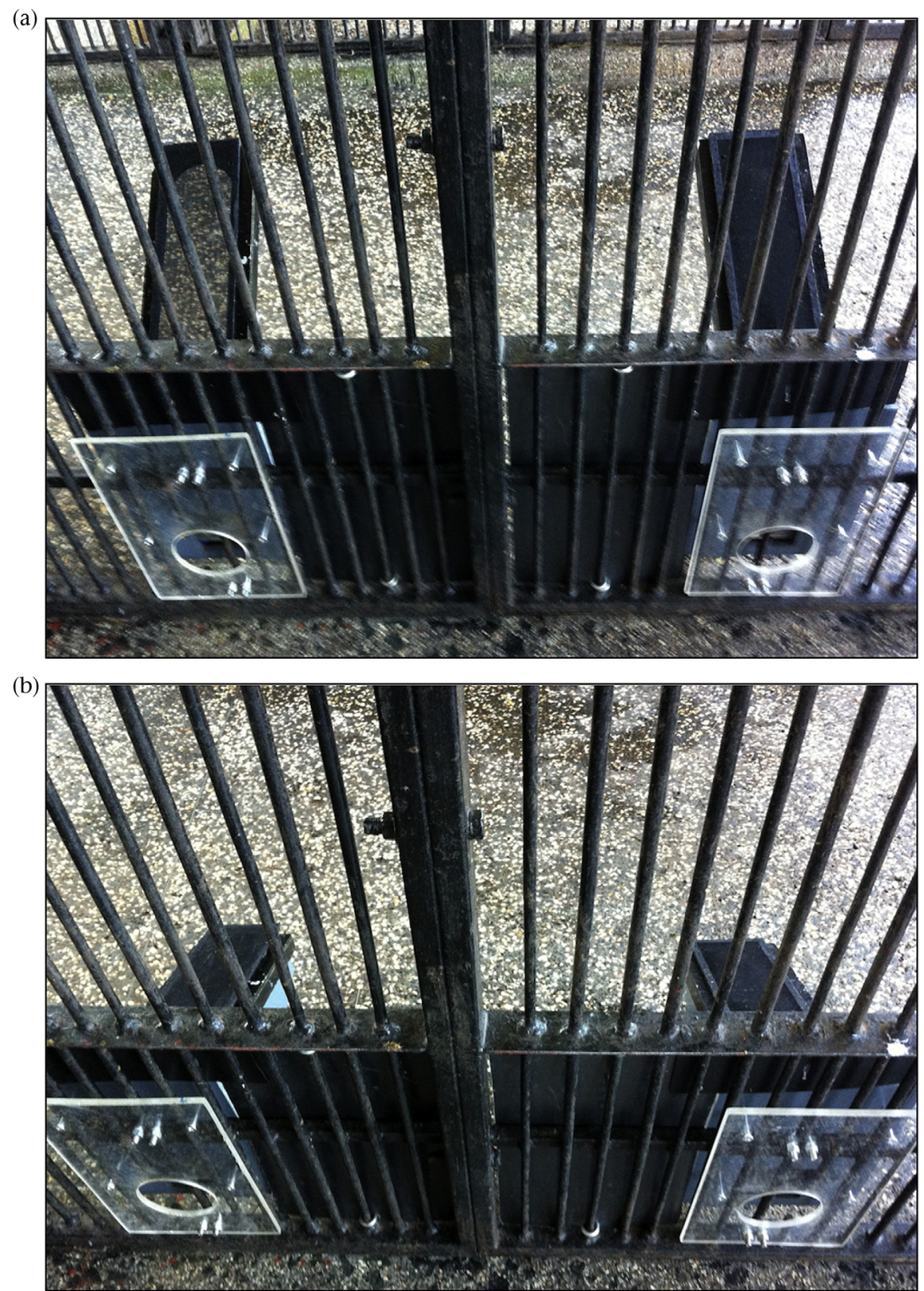

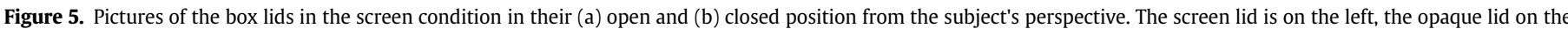
right side.

for the food underneath the transparent or the screen lid, the experimenter could see her hand and pulled back the food. If the subject chose the opaque side, on which her hand was hidden from the experimenter's view, she was allowed to take it. Note that the bars between the chimpanzee and the experimenter were occluded up to a height of $60 \mathrm{~cm}$, so that the subject could hide her approach from the experimenter. The three conditions differed in the following way.

Transparent. One lid was opaque, the other transparent.

Screen. One lid was opaque, the other a fly screen. Subjects could learn about the see-through properties of the screen while the lids were open. As soon as the lids were closed, both sides looked opaque to the subject, while the experimenter could still see through the screen. To help the subjects discriminate between the two closed lids, one of them had a green frame (whether the green frame was attached to the opaque or the screen lid was counterbalanced between subjects).

Control. To check for a general preference to choose the food underneath the opaque lid, we administered a nonsocial control. Everything was as in the transparent condition, with the only difference that the experimenter left the room after pushing the food towards the subject. The subject could then choose her preferred side independent of the presence of the human competitor. The experimenter returned after $10 \mathrm{~s}$. If the subject was quick enough, she could get both food items.

We guarded against potential cueing by having the experimenter keep her body centred, her hands in her lap and look down 
in the middle between the boxes when the subject was approaching to choose. The subject could not see the experimenter's eyes, and the experimenter could not see the subject's body when it was close to the barrier.

\section{Coding and analysis}

All trials were recorded by two cameras that focused on the boxes. For each trial, we coded which box the subject chose first by lifting the trap door (opaque/transparent/screen). An independent observer, naïve to all test parameters, coded a randomly selected $20 \%$ of the sessions. Interobserver agreement was excellent (Cohen's kappa $=0.99, P<0.001$ ). We ran a logistic regression in the R Statistical Computing Environment, using the glm function (with a binomial link function) in the lme4 package. We included trial number and order group as covariates and condition as a factor.

Results

Subjects passed the training on average after six sessions (72 trials; 95\% CI [5.21, 6.90], range 4-10 sessions). Only one male chimpanzee did not reach the criterion after 10 sessions (120 trials) and did not proceed to the test phase.

In the test, subjects selected the opaque box more frequently in the screen and transparent conditions than in the control condition (Fig. 6). Our primary analysis (see Table 1) included the control condition as the reference level of the condition factor (which includes three levels: control, screen and transparent). This models how behaviour changes by moving from the control condition (i.e. the reference level) to the screen and transparent conditions. The estimates for the screen and the transparent condition were both positive, indicating that the chimpanzees were more likely to choose the opaque box in both of these conditions than they were likely to choose the opaque box in the control condition. This
Table 1

Results of the general linear model determining whether trial number, condition order or condition influences chimpanzees' choices of the opaque box

\begin{tabular}{lrlrl}
\hline & Estimate & SE & \multicolumn{1}{l}{$z$} & $P$ \\
\hline (Intercept) & 0.030 & 0.195 & 0.152 & 0.880 \\
Trial number & 0.003 & 0.008 & 0.363 & 0.716 \\
Condition order & -0.066 & 0.068 & -0.958 & 0.338 \\
Screen & 0.354 & 0.137 & 2.587 & $\mathbf{0 . 0 1 0}$ \\
Transparent & 0.288 & 0.137 & 2.110 & $\mathbf{0 . 0 3 5}$ \\
\hline
\end{tabular}

Significant $P$ values are shown in bold.

difference is significant for both screen and transparent conditions, as the $95 \% \mathrm{CI}$ for these estimates do not include zero, and the $P$ values for both were less than 0.05 (transparent-control: $P=0.04$; screen-control: $P=0.01$ ). To explore the difference between the screen and the transparent condition, we used the same model but relevelled the condition factor so that screen was now the reference level (see Appendix Table A1). Now, examining the estimate for the transparent condition tells us whether the chimpanzees were more likely to choose the opaque box in the transparent condition than in the screen condition. We found no substantial difference between the screen and transparent conditions because the estimate for the transparent condition is small, the $95 \% \mathrm{CI}$ include zero, and the $P$ value is greater than $0.05(P=0.63)$.

We were also interested in whether chimpanzees' choices were different from chance. We conducted one-sample $t$ tests and found that chimpanzees' choice of the opaque box was significantly greater than chance in the transparent $\left(t_{17}=2.58, P=0.020\right)$ and in the screen condition $\left(t_{17}=2.28, P=0.036\right)$, but not in the control $\left(t_{17}=0.940, P=0.36\right)$.

When looking at individual performances, six (out of 18) subjects performed (nonsignificantly) above chance (50\% choice of opaque box) in both the transparent and the screen condition, four subjects performed above chance in the transparent, but not in the

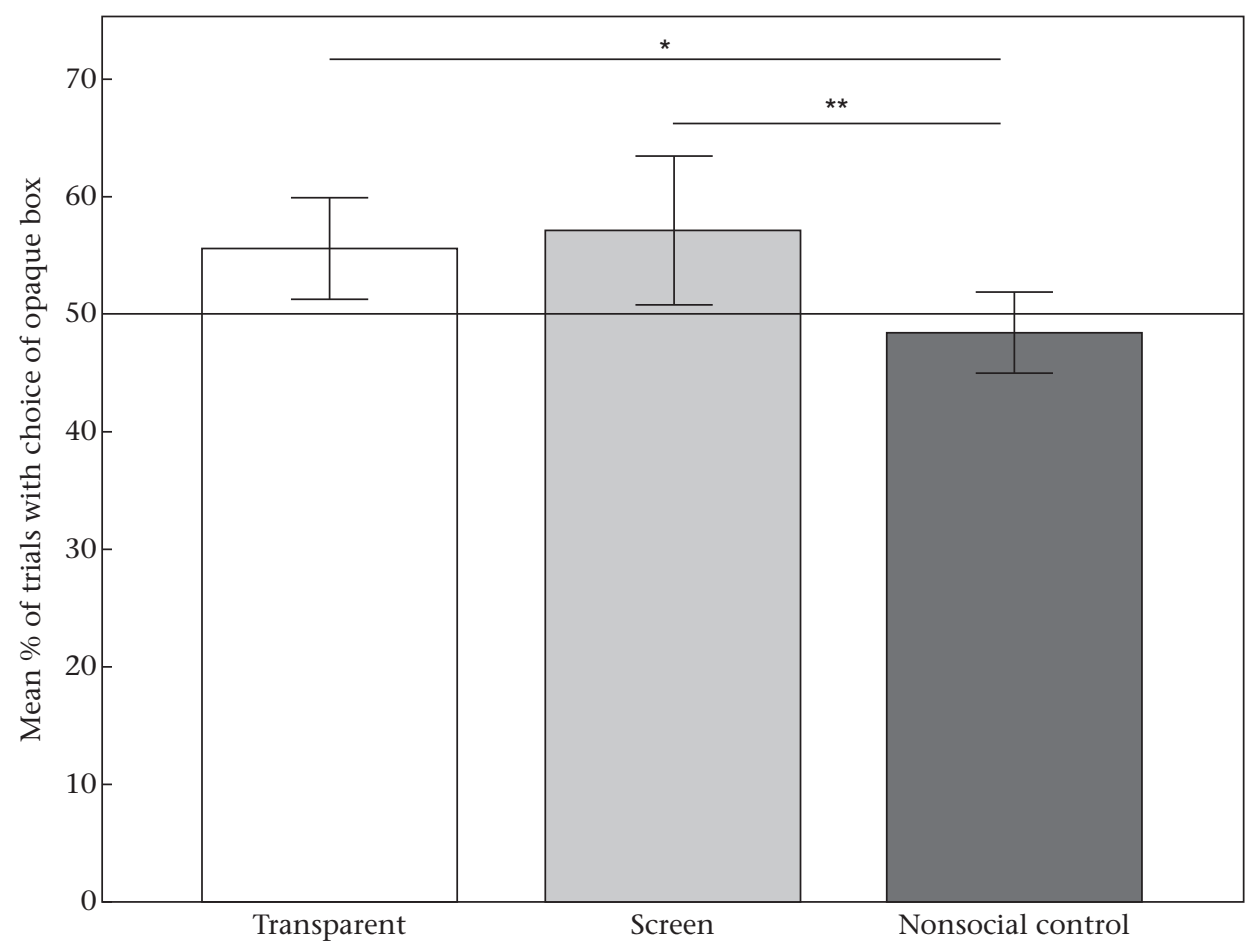

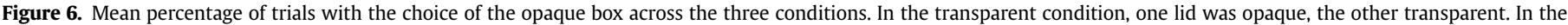

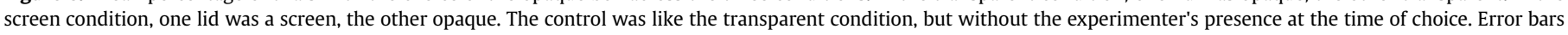
indicate $95 \% \mathrm{CI}$. The horizontal line indicates chance level $(50 \%)$. ${ }^{*} P<0.05 ;{ }^{* *} P<0.01$. 
screen condition, and four subjects performed above chance in the screen, but not in the transparent condition.

To assess learning over the course of testing, we compared each subject's performance in the first and second sessions of the transparent and the screen conditions (Appendix Fig. A1), and in the first and last trials in these conditions (in the control, both lid types were rewarded, so there was no learning opportunity). We did not observe a change in the subject's choices of the opaque box between the first and second session (paired-samples $t$ tests: transparent: $t_{17}=-1.25, P=0.23$; screen: $t_{17}=0.59, P=0.56$ ) or between the first and last trial within condition (related-samples McNemar test: transparent: $P=0.77$; screen: $P=1.0$ ). As the choice of the opaque box was rewarded in the experimental conditions, we were interested in possible carryover effects to the control. We thus conducted a between-subjects one-way ANOVA to compare the effect of zero, one or two preceding experimental conditions on the number of choices of the opaque box in the control. Without any previous experience, subjects' choice was close to chance with mean $=52.0 \%(95 \% \mathrm{CI}[45.5,58.7])$, and this did not change significantly in control conditions after one or two preceding experimental conditions $\left(F_{2,15}=1.18, P=0.33\right)$; control second: mean $=46.5 \%(95 \% \mathrm{CI}[37.2,55.9])$; control last: mean $=46.5 \%(95 \%$ CI $[40.1,53.0])$.

\section{Discussion}

In this experiment, chimpanzees were allowed to steal food from an experimenter if the experimenter could not see the stealing attempt. We found that chimpanzees preferred to steal food from an opaque box when choosing either between an opaque and a transparent box (transparent condition) or between an opaque box and a box with a screen lid that looked opaque from their perspective but not from the experimenter's and that they had experienced to be see-through earlier from a different perspective (screen condition). Interestingly, subjects performed above chance in both conditions, but not better in the (seemingly easier) transparent condition. In contrast, chimpanzees did not show a preference for the opaque box when choosing between opaque and transparent in a nonsocial control in which the experimenter was not present at the time of stealing.

These results demonstrate that chimpanzees were able to use their own experience with the visual properties of the lids to later infer in which box their approaching hand would be hidden from the experimenter. Crucially, in the moment of choice in the screen condition, both box lids appeared opaque from their perspective (and both had a screen surface), but they had experienced earlier that one could see through the screen from a different angle, but not through the opaque lid.

The results of our study confirm previous results by Melis et al. (2006) and extend them in important ways. First, we confirmed that chimpanzees conceal visual information by preferring the obscured approach route to the food over the exposed route when a human competitor is present. Notably, this preference was small both in our study (choice rate of opaque box: mean $=56 \%$ ) and in Melis et al.'s study (mean $=57 \%$ ), probably because our task is 'at the limit of what chimpanzees are capable of' (Melis et al. 2006, p. 157). Chimpanzees did not maintain the same high level of performance in the test compared to the end of the training (at least $83 \%$ correct); this was probably due to the higher cognitive challenge in the test, in which subjects could not rely on the experimenter's body orientation, but had to use their own experience with the visual properties of the lids, compared to the training (in which they could rely solely on the salient cue of the experimenter's body orientation), resulting in an additional memory problem. On top of that, subjects did not get training with the exact test situation (while they received an average of six sessions of experience with the requirements in the training). However, previous studies (Hare, Call, \& Tomasello, 2006; Melis et al. 2006; Okamoto-Barth et al. 2007; Tomasello et al. 1999) and ours consistently support the view that chimpanzees know what others can and cannot see in various situations, and that they can use this knowledge strategically in competitive or food-begging contexts (see also Bräuer, Call, \& Tomasello, 2005, 2007; Bulloch, Boysen, \& Furlong, 2008; Hostetter, Cantero, \& Hopkins, 2001; Hostetter, Russell, Freeman, \& Hopkins, 2007; Tempelmann, Kaminski, \& Liebal, 2011).

Second, our experiment adds to previous studies by confronting subjects with a situation in which they can only successfully compete if they project their self-experience with an object to the human competitor to predict what the other can see. This procedure bears the advantage that popular 'lower-level' explanations for their success do not apply here: behaviour reading or learned behavioural rules (e.g. Heyes, 1998; Penn \& Povinelli, 2007). We address three prominent concerns.

(1) Subjects could have merely reacted to behavioural cues of the experimenter, e.g. her body orientation or her gaze. We can exclude this explanation as in the test, the experimenter's body was oriented to the centre between the boxes and her gaze direction was not visible to the subject as she looked down towards the box lids.

(2) Subjects could have learnt about the effect of the lid properties on the experimenter's vision by observing her interacting with the lids. The experimenter treated all lid types in the same way. In addition, the lids were positioned such that the chimpanzee could never see the experimenter's eyes through the transparent lid or the screen. However, the lid types were differentially rewarded; while subjects were allowed to steal from the box with the opaque lid, the experimenter retrieved the food from underneath the transparent or screen lid during a stealing attempt. Therefore, subjects could potentially learn to choose the opaque box in the course of the 24 trials of each experimental condition. However, we found no evidence of improvement over time. Subjects did not choose the opaque box more often in control conditions that were preceded by one or two experimental conditions compared to naïve subjects' choice behaviour in control conditions. Within conditions, we did not observe increased success rates in the second compared to the first session or in the first compared to the last trial. Thus, although subjects could have used, for example, the coloured frames as a learning cue, they did not improve over trials.

(3) Subjects could have formed rules from observing other individuals in their natural environment and inferred the experimenter's behaviour from these rules. For example, in a prominent set of studies (Hare, Call, Agnetta, \& Tomasello, 2000; Hare, Call, \& Tomasello, 2001) subdominant chimpanzees reliably avoided food that a dominant competitor could see or had seen in the past when competing with him over two food items. While most other explanations could be excluded, one potential lower-level explanation remained. In their everyday environment, subjects could have learnt rules about the contingencies of the eyes of a competitor and contested food, for example by imagining a line of sight between the competitor's eyes and the food ('evil eyes hypothesis', see Povinelli \& Vonk, 2004). For this objection to apply to our experiment, chimpanzees would need to have experienced others looking through screens and then act as if they could see; it is unlikely that our subjects were ever exposed to such experiences as they live in a natural forest during the day and have no previous experience with experiments involving screens or others interacting with them. Moreover, in our experiment at the time of choice, the experimenter's line of sight seemed obstructed by the box lids from the 
subject's perspective for both the opaque and the screen lid. Only by projecting their experience of being able to see through the screen in the training phase, could subjects successfully avoid being caught stealing (see also Kaminski, Call, \& Tomasello, 2008; Schmelz, Call, \& Tomasello, 2011).

However, we are aware of one additional alternative explanation for our results. Following up the evil eye hypothesis, one could object that chimpanzees imagined a line of sight between the experimenter's eyes and the food, and imagined the screen in the right position such that it would not block this line. Similarly, the subjects could have learnt about the 'psychological affordances' of the masks, such as 'able to be seen through' and 'unable to be seen through', instead of projecting their visual experience to the competitor (see Meltzoff \& Brooks, 2008). The subject could then use its everyday experience to avoid the food item that is unobstructed from the competitor's view. This explanation might require them to imagine the screen from the experimenter's perspective (as from their perspective, it is 'unable to be seen through' at the moment of choice), thus forming a mental representation of an object that differs from their own. This skill, also known as level 2 perspective taking sensu Flavell and colleagues (Flavell, Everett, Croft, \& Flavell, 1981; Masangkay et al., 1974) correlates highly with classic mentalizing skills such as false belief understanding and active deception in children (even when controlling for age and language development; Bigelow \& Dugas, 2009; Farrant, Fletcher, \& Maybery, 2006). This suggests similar underlying mechanisms, in particular the ability to envision perspectives that counter one's own.

But even if subjects do not imagine the screen from the experimenter's perspective, the task at least requires them to learn about the psychological affordances of the lids by learning how it affects themselves and applying it to others (see Meltzoff \& Brooks, 2008).

\section{GENERAL DISCUSSION}

We ran two experiments that tested chimpanzees' ability to project their visual experience with an object to a human to predict what she can see. While they failed to do so in a noncompetitive gaze-following task (experiment 1 ), they were successful in a competitive context (experiment 2 ). In experiment 1 , subjects first gained experience with an opaque or transparent (but opaquelooking) face mask. Then we measured their gaze-following behaviour towards a masked experimenter. Chimpanzees did not take into account the different visual properties of the mask while following the experimenter's gaze. In contrast, Meltzoff and Brooks (2008) found in a highly similar study that 18-month-old infants followed the gaze of a blindfolded experimenter more when they had experienced the blindfolds as see-through rather than as opaque.

In experiment 2 , we tested the same question in a competitive paradigm. Subjects could steal food from an experimenter by reaching into one of two boxes. If the experimenter saw the stealing attempt, she retrieved the food. In the key condition, both box lids seemed opaque from the subject's perspective; however, they had experienced, from a different point of view, that one of the lids (the screen) was see-through while the other really was opaque. Chimpanzees preferred to reach for the food under the truly opaque lid, in which their approach was hidden from the experimenter, and avoided the screen lid through which the experimenter could see. In a nonsocial control condition, they did not show such a preference.

We argue that this experiment fulfils the requirements that sceptics propose to validly test mentalizing skills in nonhuman primates (the 'goggles experiment', e.g. Heyes, 1998; Shettleworth, 2010). First, the cue on which the inference to the mental state was made was arbitrary: in the test situation, chimpanzees could discriminate between the box lids only by the frame colour or their location. Second, subjects did not have exposure to (human or nonhuman) others behaving in association with that cue, excluding the possibility of associative learning or 'learnt behavioural rules' (and we did not find any learning effect over trials). Third, although both box lids looked opaque at the moment of choice, chimpanzees discriminated between their visual properties based on their previous self-experience, and used this knowledge appropriately to anticipate what the human competitor would be able to see. Note, however, that not all researchers accept the goggles experiment as a valid test of mental state attribution (e.g. Csibra, 1998; Lurz, 2009; Perner, 2010). Their key point is that we do not know whether chimpanzees (and other nonhuman animals) experience 'seeing' as a mental state themselves, or whether they reason about 'seeing' (even their own experience of it) nonmentalistically, for instance by experiencing seeing as having an unobstructed line of sight on an object. Thus, even if we find that chimpanzees project their own experience to others, some authors argue that this does not necessarily indicate that they project mental states to others. As Csibra (1998, p. 118) put it: 'Seeing is a mental concept if, and only if, it refers to an epistemic relation between a mind and an object/ event that is established in a particular (visual) way; but it is not a mental concept when it refers only to the physical relations that may or may not give rise to the epistemic relation. Accordingly, demonstrating that animals can understand such a physical relation and can use it as a discriminatory cue to predict the usability of people's behaviour is not sufficient evidence for applying mental concepts. What is needed in addition is to demonstrate that the animals conceive the result of seeing as a representational rather than a dispositional state'.

But if chimpanzees are able to project their self-experience to others (in whichever form), why did they not show differential gaze following towards a masked experimenter, depending on whether they experienced the mask as opaque or transparent before (experiment 1), in particular, as 18-month-old infants successfully do so (Meltzoff \& Brooks, 2008)? Several factors might account for this discrepancy. First, chimpanzees often show clearer outcomes in competitive situations, possibly due to their highly competitive environment in hierarchically organized groups (Hare \& Tomasello, 2004). In contrast, in the human world cooperation is a key feature for successful adaptation, and human infants have a natural tendency to cooperate from early on (Tomasello, 2009). This difference in ecological demands might explain why 18-month-old human infants succeeded in Meltzoff and Brooks' (2008) study, while chimpanzees failed in our highly similar experiment.

Second, whereas the gaze following required in experiment 1 is a quick and rather automatic response (although adult chimpanzees have demonstrated some flexibility in gaze following, e.g. they take into account the presence of barriers, Okamoto-Barth et al. 2007), and stop following the gaze of someone who repeatedly looks towards nothing (Tomasello et al. 2001), in experiment 2 chimpanzees had unlimited time to think about which box to choose. Although in humans, sociocognitive processes such as perspective taking have been proven to be fast and sometimes even involuntary (e.g. Samson, Apperly, Braithwaite, Andrews, \& Bodley Scott, 2010; Surtees \& Apperly, 2012), these processes might be computed more slowly in great apes, and thus be captured better with more explicit behavioural measures.

Third, while subjects could use only the frame colour as a cue to the visual properties of the mask in experiment 1 , they could use frame colour and/or location of the lid (left/right of the experimenter) as a cue in the second study. Obviously, the location of the rewarded lid varied randomly between the trials; however, in the experience phase of each trial, they could learn not only about the 
frame colour, but also about the location of the (truly) opaque lid. Several studies have demonstrated that chimpanzees have difficulties with quickly associating arbitrary cues such as colour with the presence of food (e.g. Call, 2006; Jarvik, 1953, 1956), which might account for their indiscriminate gaze-following behaviour in experiment 1 . Other studies show that chimpanzees prefer location to colour as a cue to find food (e.g. Haun, Call, Janzen, \& Levinson, 2006; Tinklepaugh, 1932; but see also Kanngiesser \& Call, 2010, for contradictory results). The additional informative spatial feature might thus have helped chimpanzees to choose the correct box in experiment 2 .

After dozens of positive findings that show that chimpanzees understand what others see or hear (Bräuer, Call, \& Tomasello, 2007; Hare et al. 2000; Melis et al. 2006), prefer (Schmelz, Call, \& Tomasello, 2013), know (Hare et al. 2001; Kaminski et al. 2008), attend to (MacLean \& Hare, 2012), intend (Behne, Carpenter, Call, \& Tomasello, 2005; Buttelmann, Carpenter, Call, \& Tomasello, 2007; Call, Hare, Carpenter, \& Tomasello, 2004; Call \& Tomasello, 1998; Warneken \& Tomasello, 2006) and infer (Schmelz et al. 2011), this study provides additional evidence that chimpanzees possess mentalizing capacities revealed by a different and powerful method. Because subjects used their self-experience to infer what the competitor saw, the current results might fit best with Meltzoff's 'Like Me' framework (2007).

Overall, we thus agree with Whiten's (2013, p. 213) recent evaluation of the state of the art of the field: 'Humans are not alone in computing how others see the world'. As the methodology of the current study is based on suggestions of sceptics in the field, it would seem to constitute especially powerful additional evidence for this proposal.

\section{Acknowledgments}

We are grateful to the director L. Ajarova, the trustees and all the staff of the Chimpanzee Sanctuary and Wildlife Conservation Trust for allowing research on Ngamba Island. Many special thanks to the caregivers for their continuous and selfless help and support. We thank E. Herrmann for organizational support, R. Pieszek for building the apparatus, M. Schumann for creating graphics, B. House for statistical advice and M. Thiele and B. Schmid for reliability coding. We appreciate permission to conduct research in Uganda from the Ugandan National Council for Science and Technology and the Uganda Wildlife Authority. We thank two anonymous referees for their helpful comments on the manuscript. K.K. also gratefully acknowledges financial support from the German National Academic Foundation.

\section{References}

Andrews, K. (2005). Chimpanzee theory of mind: looking in all the wrong places. Mind \& Language, 20(5), 521-536. http://dx.doi.org/10.1111/j.02681064.2005.00298.x.

Behne, T., Carpenter, M., Call, J., \& Tomasello, M. (2005). Unwilling versus unable: infants' understanding of intentional action. Developmental Psychology, 41(2), 328-337. http://dx.doi.org/10.1037/0012-1649.41.2.328.

Bigelow, A. E., \& Dugas, K. (2009). Relations among preschool children's understanding of visual perspective taking false belief and lying. Journal of Cognition and Development, 9(4), 411-433. http://dx.doi.org/10.1080/ 15248370802678299.

Bräuer, J., Call, J., \& Tomasello, M. (2005). All great ape species follow gaze to distant locations and around barriers. Journal of Comparative Psychology, 119(2), 145-154. http://dx.doi.org/10.1037/0735-7036.119.2.145.

Bräuer, J., Call, J., \& Tomasello, M. (2007). Chimpanzees really know what others can see in a competitive situation. Animal Cognition, 10(4), 439-448. http:// dx.doi.org/10.1007/s10071-007-0088-1.

Bulloch, M. J., Boysen, S. T., \& Furlong, E. E. (2008). Visual attention and its relation to knowledge states in chimpanzees Pan troglodytes. Animal Behaviour, 76(4), 1147-1155. http://dx.doi.org/10.1016/j.anbehav.2008.01.033.
Butler, S. C., Caron, A. J., \& Brooks, R. (2000). Infant understanding of the referential nature of looking. Journal of Cognition and Development, 1(4), 359-377. http:// dx.doi.org/10.1207/S15327647JCD0104_01.

Buttelmann, D., Carpenter, M., Call, J., \& Tomasello, M. (2007). Enculturated chimpanzees imitate rationally. Developmental Science, 10(4), F31-F38. http:/ dx.doi.org/10.1111/j.1467-7687.2007.00630.x.

Call, J. (2006). Descartes' two errors: reason and reflection in the great apes. In S. L. Hurley, \& M. Nudds (Eds.), Rational animals? (pp. 219-234). Oxford, U.K. Oxford University Press,. $\quad$ http://dx.doi.org/10.1093/acprof:oso/ 9780198528272.003 .0010

Call, J. (2007). Past and present challenges in theory of mind research in nonhuman primates. Progress in Brain Research, 164(2700), 341-353. http://dx.doi.org 10.1016/S0079-6123(07)64019-9.

Call, J., Hare, B., Carpenter, M., \& Tomasello, M. (2004). 'Unwilling' versus 'unable': chimpanzees' understanding of human intentional action. Developmental Science, 7(4), 488-498. http://dx.doi.org/10.1111/j.14677687.2004.00368.x.

Call, J., \& Tomasello, M. (1998). Distinguishing intentional from accidental actions in orangutans (Pongo pygmaeus) chimpanzees (Pan troglodytes) and human children (Homo sapiens). Journal of Comparative Psychology, 112(2), 192-206. http:// dx.doi.org/10.1037/0735-7036.112.2.192.

Call, J., \& Tomasello, M. (2008). Does the chimpanzee have a theory of mind? 30 years later. Trends in Cognitive Sciences, 12(5), 187-192. http://dx.doi.org/ 10.1016/j.tics.2008.02.010.

Csibra, G. (1998). Seeing is not believing. Behavioral and Brain Sciences, 21(01), 117-118. http://dx.doi.org/10.1017/S0140525X98250709.

Dunphy-Lelii, S., \& Wellman, H. M. (2004). Infants' understanding of occlusion of others' line-of-sight: implications for an emerging theory of mind. European Journal of Developmental Psychology, 1(1), 49-66. http://dx.doi.org/10.1080/ 17405620444000049.

Farrant, B. M., Fletcher, J., \& Maybery, M. T. (2006). Specific language impairment theory of mind and visual perspective taking: evidence for simulation theory and the developmental role of language. Child Development, 77(6), 1842-1853. http://dx.doi.org/10.1111/j.1467-8624.2006.00977.x.

Flavell, J. H., Everett, B. A., Croft, K., \& Flavell, E. R. (1981). Young children's knowledge about visual perception: further evidence for the level 1 level 2 distinction. Developmental Psychology, 17(1), 99-103. http://dx.doi.org/10.1037/ 0012-1649.17.1.99.

Hare, B., Call, J., Agnetta, B., \& Tomasello, M. (2000). Chimpanzees know what conspecifics do and do not see. Animal Behaviour, 59(4), 771-785. http:/ dx.doi.org/10.1006/anbe.1999.1377.

Hare, B., Call, J., \& Tomasello, M. (2001). Do chimpanzees know what conspecifics know? Animal Behaviour, 61(1), 139-151. http://dx.doi.org/10.1006 anbe.2000.1518.

Hare, B., Call, J., \& Tomasello, M. (2006). Chimpanzees deceive a human competitor by hiding. Cognition, 101(3), 495-514. http://dx.doi.org/10.1016 j.cognition.2005.01.011.

Hare, B., \& Tomasello, M. (2004). Chimpanzees are more skilful in competitive than in cooperative cognitive tasks. Animal Behaviour, 68(3), 571-581. http:// dx.doi.org/10.1016/j.anbehav.2003.11.011.

Haun, D., Call, J., Janzen, G., \& Levinson, S. C. (2006). Evolutionary psychology of spatial representations in the hominidae. Current Biology, 16(17), 1736-1740. http://dx.doi.org/10.1016/j.cub.2006.07.049.

Heyes, C. M. (1998). Theory of mind in nonhuman primates. Behavioral and Brain Sciences, 21(1), 101-114. http://dx.doi.org/10.1017/S0140525X98000703.

Hostetter, A. B., Cantero, M., \& Hopkins, W. D. (2001). Differential use of vocal and gestural communication by chimpanzees (Pan troglodytes) in response to the attentional status of a human (Homo sapiens). Journal of Comparative Psychology, 115(4), 337-343. http://dx.doi.org/10.1037//0735-7036.115.4.337.

Hostetter, A. B., Russell, J. L., Freeman, H., \& Hopkins, W. D. (2007). Now you see me now you don't: evidence that chimpanzees understand the role of the eyes in attention. Animal Cognition, 10(1), 55-62. http://dx.doi.org/10.1007/s10071006-0031-X.

Jarvik, M. E. (1953). Discrimination of colored food and food signs by primates. Journal of Comparative and Physiological Psychology, 46(5), 390-392. http:// dx.doi.org/10.1037/h0054308.

Jarvik, M. E. (1956). Simple color discrimination in chimpanzees: effect of varying contiguity between cue and incentive. Journal of Comparative and Physiological Psychology, 49(5), 492-495. http://dx.doi.org/10.1037/h0045644.

Kaminski, J., Call, J., \& Tomasello, M. (2008). Chimpanzees know what others know but not what they believe. Cognition, 109(2), 224-234. http://dx.doi.org/ 10.1016/j.cognition.2008.08.010.

Kanngiesser, P., \& Call, J. (2010). Bonobos chimpanzees gorillas and orangutans use feature and spatial cues in two spatial memory tasks. Animal Cognition, 13(3), 419-430. http://dx.doi.org/10.1007/s10071-009-0291-3.

Lurz, R. W. (2009). If chimpanzees are mindreaders could behavioral science tell? Toward a solution of the logical problem. Philosophical Psychology, 22(3), 305-328. http://dx.doi.org/10.1080/09515080902970673.

MacLean, E. L., \& Hare, B. (2012). Bonobos and chimpanzees infer the target of another's attention. Animal Behaviour, 83(2), 345-353. http://dx.doi.org 10.1016/j.anbehav.2011.10.026

Masangkay, Z. S., McCluskey, K. A., McIntyre, C. W., Sims-Knight, J., Vaughn, B. E., \& Flavell, J. H. (1974). The early development of inferences about the visual percepts of others. Child Development, 45(2), 357-366. http://dx.doi.org/10.2307/ 1127956 
Melis, A. P., Call, J., \& Tomasello, M. (2006). Chimpanzees (Pan troglodytes) conceal visual and auditory information from others. Journal of Comparative Psychology, 120(2), 154-162. http://dx.doi.org/10.1037/0735-7036.120.2.154.

Meltzoff, A. N. (2007). 'Like Me': a foundation for social cognition. Developmental Science, 10(1), 126-134. http://dx.doi.org/10.1111/j.1467-7687.2007.00574.x.

Meltzoff, A. N., \& Brooks, R. (2008). Self-experience as a mechanism for learning about others: a training study in social cognition. Developmental Psychology, 44(5), 1257-1265. http://dx.doi.org/10.1037/a0012888.

Okamoto-Barth, S., Call, J., \& Tomasello, M. (2007). Great apes' understanding of other individuals' line of sight. Psychological Science, 18(5), 462-468. http:// dx.doi.org/10.1111/j.1467-9280.2007.01922.x.

Penn, D. C., \& Povinelli, D. J. (2007). On the lack of evidence that non-human animals possess anything remotely resembling a 'Theory of Mind'. Philosophical Transactions of the Royal Society of London B: Biological Sciences, 362(1480), 731-744. http://dx.doi.org/10.1098/rstb.2006.2023.

Perner, J. (2010). Who took the cog out of cognitive science? In P. A. Frensch, \& R. Schwarzer (Eds.), Cognition and neuropsychology: International perspectives on psychological science 1 (pp. 241-261) Hove, U.K.: Psychology Press.

Povinelli, D. J., \& Vonk, J. (2003). Chimpanzee minds: suspiciously human? Trends in Cognitive Sciences, 7(4), 157-160.

Povinelli, D. J., \& Vonk, J. (2004). We don't need a microscope to explore the chimpanzee's mind. Mind \& Language, 19(1), 1-28. http://dx.doi.org/10.1111/ j.1468-0017.2004.00244.x.

Premack, D., \& Woodruff, G. (1978). Does the chimpanzee have a theory of mind? Behavioral and Brain Sciences, 1(4), 515-526. http://dx.doi.org/10.1017 S0140525X00076512.

Purdy, J. E., \& Domjan, M. (1998). Tactics in theory of mind research. Behavioral and Brain Sciences, 21(1), 129-130. http://dx.doi.org/10.1017/S0140525X98390706.

Samson, D., Apperly, I. A., Braithwaite, J. J., Andrews, B. J., \& Bodley Scott, S. E. (2010). Seeing it their way: evidence for rapid and involuntary computation of what other people see. Journal of Experimental Psychology: Human Perception and Performance, 36(5), 1255-1266. http://dx.doi.org/10.1037/a0018729.

Schmelz, M., Call, J., \& Tomasello, M. (2011). Chimpanzees know that others make inferences. Proceedings of the National Academy of Sciences of the United States of America, 108(7), 3077-3079. http://dx.doi.org/10.1073/pnas.1000469108.

Schmelz, M., Call, J., \& Tomasello, M. (2013). Chimpanzees predict that a competitor's preference will match their own. Biology Letters, 9(1). http://dx.doi.org/ 10.1098/Rsbl.2012.0829.

Shettleworth, S. J. (2010). Clever animals and killjoy explanations in comparative psychology. Trends in Cognitive Sciences, 14(11), 477-481. http://dx.doi.org/ 10.1016/J.Tics.2010.07.002.

Surtees, A. D. R., \& Apperly, I. A. (2012). Egocentrism and automatic perspective taking in children and adults. Child Development, 83(2), 452-460. http:// dx.doi.org/10.1111/j.1467-8624.2011.01730.x.

Tempelmann, S., Kaminski, J., \& Liebal, K. (2011). Focus on the essential: all great apes know when others are being attentive. Animal Cognition, 14(3), 433-439. http://dx.doi.org/10.1007/s10071-011-0378-5.

Tinklepaugh, O. L. (1932). The multiple delayed reaction with chimpanzees and monkeys. Journal of Comparative Psychology, 13(2), 207. http://dx.doi.org/ 10.1037/h0072368.

Tomasello, M. (2009). Why we cooperate, Cambridge, MA: MIT Press.

Tomasello, M., Call, J., \& Hare, B. (1998). Five primate species follow the visual gaze of conspecifics. Animal Behaviour, 55(4), 1063-1069. http://dx.doi.org/10.1006 anbe.1997.0636.

Tomasello, M., Hare, B., \& Agnetta, B. (1999). Chimpanzees Pan troglodytes follow gaze direction geometrically. Animal Behaviour, 58(4), 769-777. http:// dx.doi.org/10.1006/anbe.1999.1192.

Tomasello, M. Hare, B., \& Fogleman, T. (2001). The ontogeny of gaze following in chimpanzees Pan troglodytes and Rhesus Macaques Macaca mulatta. Animal Behaviour, 61(2), 335-343. http://dx.doi.org/10.1006/anbe.2000.1598.

Tomasello, M., Hare, B., Lehmann, H., \& Call, J. (2007). Reliance on head versus eyes in the gaze following of great apes and human infants: the cooperative eye hypothesis. Journal of Human Evolution, 52(3), 314-320.

Vonk, J., \& Povinelli, D. J. (2011). Social and physical reasoning in human-reared chimpanzees: preliminary studies. In N. Eilan, H. Lerman, \& J. Roessler (Eds.) Perception, causation, and objectivity. Issues in philosophy and psychology (pp. 342-352). Oxford, U.K.: Oxford University Press,.
Warneken, F., \& Tomasello, M. (2006). Altruistic helping in human infants and young chimpanzees. Science, 311(5765), 1301-1303. http://dx.doi.org/10.1126/ science. 1121448 .

Whiten, A. (2013). Humans are not alone in computing how others see the world. Animal Behaviour, 86(2), 213-221. http://dx.doi.org/10.1016 J.Anbehav.2013.04.021.

\section{APPENDIX}

Table A1

Results of the general linear model determining whether trial number, condition order or condition influences chimpanzees' choices of the opaque box, with the screen condition as the reference level

\begin{tabular}{lclrl}
\hline & Estimate & SE & \multicolumn{1}{l}{$z$} & $P$ \\
\hline (Intercept) & 0.038 & 0.196 & 1.957 & 0.050 \\
Trial number & 0.003 & 0.008 & 0.363 & 0.716 \\
Condition order & -0.066 & 0.068 & -0.958 & 0.338 \\
Control & -0.354 & 0.137 & -2.587 & $\mathbf{0 . 0 1 0}$ \\
Transparent & -0.066 & 0.137 & -0.480 & 0.631
\end{tabular}

Significant $P$ value is shown in bold.

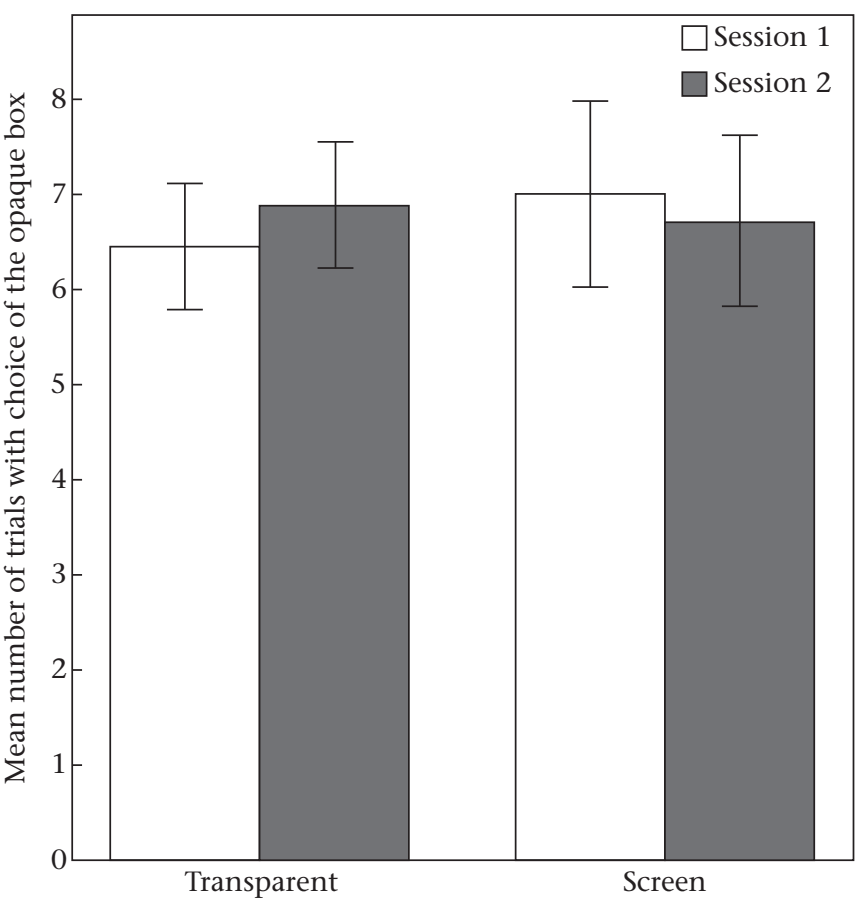

Condition

Figure A1. Comparison of the chimpanzees' choices of the opaque box in the first and second session of the transparent and the screen condition in experiment 2. Error bars indicate $95 \% \mathrm{CI}$. 